\title{
Parameter reproduktif yang berhubungan dengan kejadian hipertensi pada wanita
}

\author{
Nuke Devi Indrawati ${ }^{{ }^{*}}$, Dewi Puspitaningrum ${ }^{2}$, Dian Nintyasari Mustika ${ }^{3}$, \\ Maria Ulfa Kurnia Dewi ${ }^{4}$ \\ ${ }^{1,2,3}$ Prodi D III Kebidanan; ${ }^{4}$ Prodi S1 Kebidanan dan Profesi Bidan, Fakultas Ilmu Keperawatan dan \\ Kesehatan, Universitas Muhammadiyah Semarang, Indonesia
}

\begin{abstract}
Background: Hypertension is one of the biggest killer diseases in the world. Reproductive parameters such as age, parity and hormonal contraception are considered parameters related to reproductive history that may play a role in the occurrence of hypertension events. The purpose of this study is to find out the age, parity and hormonal contraceptives with the incidence of hypertension in elderly women in Tlogosari Kulon Health Center. Method : Type of analytical research, with cross-sectional study approach. The random research population in WUS in Tembalang Village, Semarang city numbered 128 respondents. The instrument used is a questionnaire. The data analysis was conducted univariately, bivariately using the Chi Square test. The results of the study: from 128 with the age of 40-45 th $50 \%$, parity of the majority entered multipara $76 \%$, long use of hormonal contraceptives majority $\geq 10$ years $94 \%$ and work as a public and private employee as much as $36.71 \%$. Bivariate analysis relationship tests showed there were variables namely age ( $p$ value 0.028$)$, parity ( $p$ value 0.456 ), hormonal contraceptives ( $p$ value 1,000) and employment ( $p$ value 0.012 ). Conclusion: There is a relationship between age and occupation with the incidence of hypertension in elderly women in Tembalang Village, Semarang.
\end{abstract}

Keywords: job; hormonal contraception; parity; age

Latar Belakang: Hipertensi merupakan salah satu penyakit pembunuh terbesar di dunia. Parameter reproduktif seperti umur, paritas dan kontrasepsi hormonal dianggap sebagai parameter yang terkait dengan sejarah reproduksi yang mungkin berperan dalam terjadinya kejadian hipertensi. Tujuan penelitian ini adalah untuk mengetahui usia, paritas dan kontrasepsi hormonal dengan kejadian hipertensi pada lansia perempuan di Puskesmas Tlogosari Kulon. Metode: Jenis penelitian analitik, dengan pendekatan studi cross-sectional. Populasi penelitian secara random pada WUS yang ada di Kelurahan Tembalang, Kota Semarang berjumlah 128 responden. Instrumen yang digunakan adalah kuesioner. Analisis data dilakukan secara univariat, secara bivariat menggunakan uji Chi Square. Hasil Penelitian: dari 128 dengan usia $40-45$ th $50 \%$, paritas mayoritas masuk multipara $76 \%$, lama menggunakan kontrasepsi hormonal mayoritas $\geq 10$ tahun $94 \%$ dan pekerjaan sebagai pegawai negeri dan swasta sebanyak $36,71 \%$. Uji hubungan analisis bivariat menunjukkan terdapat variabel yaitu umur ( $p$ value 0,028 ), paritas ( $p$ value 0,456 ), kontrasepsi hormonal ( $p$ value 1,000 ) dan pekerjaan ( $p$ value 0,012 ). Kesimpulan : Ada hubungan antara umur dan pekerjaan dengan kejadian hipertensi pada lansia perempuan di Kelurahan Tembalang Kota Semarang.

\footnotetext{
*Corresponding Author: Nuke Devi Indrawati (email: nukedevi@unimus.ac.id)
} 
Kata Kunci: pekerjaan; kontrasepsi hormonal; paritas; usia; hipertensi

\section{Pendahuluan}

Hipertensi menjadi masalah utama tidak hanya di Indonesia tapi di dunia, karena hipertensi ini merupakan salah satu pintu masuk atau faktor risiko penyakit seperti jantung, gagal ginjal, diabetes, stroke (Riskesdas, 2018).

\section{Data World Health Organization} (WHO) tahun 2015 menunjukkan sekitar 1,13 Miliar orang di dunia menyandang hipertensi, artinya 1 dari 3 orang di dunia terdiagnosis hipertensi. Jumlah penyandang hipertensi terus meningkat setiap tahunnya, diperkirakan pada tahun 2025 akan ada 1,5 Miliar orang yang terkena hipertensi, dan diperkirakan setiap tahunnya 9,4 juta orang meninggal akibat hipertensi dan komplikasinya (Riskesdas,2018).

Data dari Dinas Kesehatan Jawa Tengah menyebutkan pada tahun 2017 lalu urutan kedua PTM adalah diabetes militus (22\%) dan asma (7\%). Sementara di tahun 2018, penyakit hipertensi ada di urutan kedua dengan 18,7\%. Terjadi pergeseran jenis penyakit tidak menular (PTM) yang menyerang masyarakat Jawa Tengah. Jika pada tahun 2017, persentase tertinggi adalah hipertensi (56\%) maka pada tahun 2018 daftar tertinggi diduduki oleh penyakit Jantung (43\%) (Dinkes Prov Jateng, 2019).
Data PTM di Kota Semarang tahun 2019 terjadi peningkatan. Prevalensi Hipertensi Kota Semarang sebesar 37\% dihitung dari Jumlah Penduduk $\geq 15$ tahun, Prevalensi DM Kota Semarang 3,1\% dihitung dari jumlah Penduduk $\geq 15$ tahun (Pemkot Semarang, 2019).

Hipertensi merupakan penyakit yang sebenarnya dapat dicegah (Suryandari, 2009). Banyak faktor yang mempengaruhi terjadinya hipertensi baik faktor risiko yang dapat diubah yaitu kebiasaan merokok, obesitas, penggunaan kontrasepsi hormonal (estrogen), alkohol, kafein, stres, konsumsi garam, kolestrol, kurang gerak maupun faktor risiko yang tidak dapat diubah yaitu keturunan, ras, jenis kelamin dan usia (Fauzi, 2014) yang menjadikannya penyebab utama morbiditas dan mortalitas dapat berkontribusi untuk risiko seorang wanita untuk hipertensi. (Seow et al., 2015) Bertambahnya umur pada usia lanjut beresiko lebih besar untuk terkena hipertensi yang disebabkan adanya penebalan zat kolagen pada lapisan otot (Prayitno, 2013).

Paritas didefinisikan sebagai berapa kali wanita melahirkan atau jumlah kelahiran bayi yang dapat bertahan hidup di dunia. 
(Seow et al., 2015) Pada penelitian sebelumnya, paritas terbukti memiliki efek positif yang sangat signifikan terhadap tekanan darah dan hipertensi, kemudian Penelitian lain di lapangan tidak menunjukkan hubungan yang signifikan. Penelitian yang menunjukkan efek signifikan paritas pada tekanan darah dan Hipertensi berkaitan dengan hubungan kehamilan dan faktor risiko hipertensi. (Giubertoni et al., 2013)

Terbentuk kenaikan tekanan darah mungkin karena beberapa patologi, seperti kehamilan atau obat-obatan seperti kontrasepsi hormonal. (Giubertoni et al., 2013) Efek samping yang paling ditakuti pada pemakaian kontrasepsi hormonal adalah timbulnya penyakit pada sistem kardiovaskuler juga meningkatkan risiko terkena hipertensi. (Giubertoni et al., 2013)

Badan penelitian kesehatan dunia World Health Organization (WHO), secara global keseluruhan prevalensi hipertensi pada orang dewasa berusia 40 tahun keatas sekitar $40 \%$, prevalensi hipertensi diprediksikan tahun
2025 orang dewasa akan menderita hipertensi di seluruh dunia sekitar 29\%. (WHO, 2015)

Kejadian penyakit hipertensi di Kelurahan Tembalang Kota Semarang tergolong tinggi. Meskipun dari tahun ke tahun penyakit hipertensi semakin menurun.

\section{Metode}

Jenis penelitian analitik, dengan pendekatan studi cross-sectional. Populasi penelitian secara random pada PUS (36-49) yang ada di Kelurahan Tembalang, Kota Semarang berjumlah 128 responden. Instrumen yang digunakan adalah kuesioner. Analisis data dilakukan secara univariat, secara bivariat menggunakan uji Chi Square.

\section{Hasil dan Pembahasan}

Berdasarkan Tabel 1. Variabel distribusi frekuensi diketahui umur mayoritas 40-45th $50 \%$, paritas mayoritas masuk multipara $76 \%$, lama pemakaian kontrasepsi hormonal mayoritas $\geq 10$ tahun $94 \%$, pekerjaan antara PNS dan swasta pekerja sama $36,71 \%$. 
Tabel 1. Distribusi Frekuensi Variabel Univariat

\begin{tabular}{lcc}
\hline \multicolumn{1}{c}{ Variabel } & Frekuensi & Persentase (\%) \\
\hline Umur & 46 & 35,93 \\
$36-39$ & 50 & 39,06 \\
$40-45$ & 32 & 25 \\
$46-49$ & 128 & $\mathbf{1 0 0 , 0}$ \\
Total & & \\
Paritas & 52 & 40,62 \\
Grandemultipara (>4) & 76 & 59,37 \\
Multipara (<4) & 128 & $\mathbf{1 0 0 , 0}$ \\
Total & & \\
Lama Penggunaan kontrasepsi hormonal & 34 & 26,56 \\
$<10$ tahun & 94 & $\mathbf{7 3 , 4 3}$ \\
$\geq 10$ tahun & 128 & $\mathbf{1 0 0 , 0}$ \\
Total & & \\
Pekerjaan & 34 & 26,56 \\
IRT & 47 & 36,71 \\
Swasta & 47 & 36,71 \\
PNS & 128 & $\mathbf{1 0 0 , 0}$ \\
Total & & \\
Kejadian Hipertensi & 89 & 69,53 \\
Hipertensi $\geq 140 / 90 \mathrm{mmHg}$ & 39 & 30,46 \\
Normal $<140 / 90 \mathrm{mmHg}$ & $\mathbf{1 2 8}$ & $\mathbf{1 0 0 , 0}$ \\
Total & & \\
\hline
\end{tabular}

Berdasarkan Tabel 2 hubungan antara

variabel bebas dan terikat berdasarkan uji Chi Square diketahui bahwa terdapat hubungan antara variabel umur dengan $p$ value $=0,028$, variabel paritas sendiri tidak memiliki hubungan dengan $p$ value $=0,456$ dan lama penggunaan kontrasepsi hormonal dengan $p$ value $=1,000$, variabel pekerjaan bahwa terdapat hubungan antara variabel pekerjaan dengan $p$ value $=0,012$.

Hasil analisis data diketahui terdapat hubungan antara variabel umur dengan kejadian hipertensi. peningkatan usia maka terjadilah proses-proses degeneratif pada semua organ terutama organ untuk system sirkulasi yaitu jantung dan pembuluh darah. Hal ini juga sesuai penelitian sebelumya bahwa makin meningkatnya usia maka makin meningkat juga risiko terjadinya hipertensi yang disebabkan oleh proses degenerative. (Giubertoni et al., 2013) Akibat bertambahnya umur, terjadi penurunan fungsi fisiologis dan daya tahan tubuh yang terjadi karena proses penuaan yang dapat menyebabkan seseorang rentan terhadap penyakit salah satunya yaitu hipertensi (Kementerian Kesehatan RI, 2013). Berdasarkan penelitian dari para ahli di Belanda yang diterbitkan di jurnal Human Repro- 
duction tahun 2014 menunjukkan bahwa hun, kesempatannya adalah sekitar 88\%. penelitian pada lebih dari 58.000 responden, Bahkan, wanita yang berumur 38 tahun masih wanita umur 30 tahun punya kesempatan memiliki kesempatan sebesar $80 \%$ (Kersten et memiliki anak sebesar 93\%. Pada umur 35 taal., 2015).

Tabel 2. Distribusi Frekuensi Variabel Bivariat

\begin{tabular}{|c|c|c|c|c|c|c|c|}
\hline \multirow[t]{3}{*}{ Variabel } & \multicolumn{4}{|c|}{ Kapasitas Vital Paru } & \multicolumn{2}{|r|}{ Total } & \multirow[t]{3}{*}{$P$ value } \\
\hline & \multicolumn{2}{|c|}{ Hipertensi } & \multicolumn{2}{|r|}{ Normal } & & & \\
\hline & $\mathrm{N}$ & $\%$ & $\mathrm{n}$ & $\%$ & $\mathrm{~N}$ & $\%$ & \\
\hline \multicolumn{8}{|l|}{ Umur } \\
\hline $36-39$ & 27 & 58,69 & 19 & 41,30 & 46 & 100.0 & \\
\hline $40-45$ & 32 & 64 & 27 & 54 & 50 & 100,0 & 0,028 \\
\hline $46-49$ & 26 & 68,43 & 12 & 31,57 & 38 & 100,0 & \\
\hline \multicolumn{8}{|l|}{ Paritas } \\
\hline Grandemultipara & 45 & 80,35 & 11 & 19,64 & 56 & 100,0 & 0,456 \\
\hline Multipara & 18 & 25 & 54 & 75 & 72 & 100,0 & \\
\hline \multicolumn{8}{|c|}{ Lama penggunaan kontrasepsi hormonal } \\
\hline$<10$ tahun & 22 & 70,96 & 9 & 29,03 & 31 & 100,0 & 1,000 \\
\hline$\geq 10$ tahun & 86 & 88,65 & 42 & 43,29 & 97 & 100,0 & \\
\hline \multicolumn{8}{|l|}{ Pekerjaan } \\
\hline IRT & 18 & 75 & 6 & 25 & 24 & 100,0 & \\
\hline Swasta & 42 & 65,62 & 38 & 59,37 & 64 & 100,0 & 0,012 \\
\hline PNS & 28 & 70 & 12 & 30 & 40 & 100,0 & \\
\hline
\end{tabular}

Catatan $*=p$ value $<0,05$ (tidak ada hubungan).

Variabel Paritas berdasarkan analisis data diketahui tidak ada hubungan antara paritas dengan Kejadian hipertensi. Jumlah kehamilan seorang wanita memiliki dapat mempengaruhi tekanan darah karena perubahan fisiologis pada perfusi darah selama kehamilan. (Ardiansyah, 2012) Hasil penelitian ini sejalan dengan penelitian yang telah dilakukan sebelumnya bahwa tidak ada hubungan antara paritas dengan kejadian hipertensi (Giubertoni, 2013).
Hasil analisis data diketahui bahwa tidak ada hubungan antara lama penggunaan kontrasepsi hormonal dengan kejadian hipertensi. Akan tetapi hal ini berbeda dengan hasil peneliti lainnya bahwa Penggunaan pil KB lebih dari 12 tahun secara statistik merupakan faktor risiko terjadinya hipertensi (Sugiharto et al., 2007).

Pekerjaan dalam arti luas merupakan suatu aktifiats utama yang dilakukan oleh seseorang. Sedangkan dalam pengertian sempit adalah suatu tugas yang menghasilkan uang 
bagi seseorang (Arda, et al., 2018). Terkait dengan pekerjaan bahwa banyaknya pekerjaan yang menyita waktu mengakibatkan manusia mengalami stres akan pekerjaan yang merupakan respon fisiologi, psikologi, dan perilaku seseorang untuk penyesuaian diri terhadap tekanan. Stres psikologis juga dapat merangsang ginjal melepaskan hormon adrenalin yang menyebabkan tekanan darah naik dan meningkatkan kekentalan darah (Arif and
Hartinah, 2013). Penelitian ini sejalan dengan hasil penelitian yang dilakukan Kartikasari bahwa pekerjaan merupakan factor resiko terjadinya hipertensi (Kartikasari, 2012).

Akan tetapi tidak sejalan dengan penelitian yang dilakukan oleh Aris Sugiharto, yang menyatakan bahwa jenis kesibukan merupakan faktor resiko terjadinya hipertensi (Sugiharto et al., 2007).

Tabel 3. Hubungan antara Paritas dengan Pemilihan Alat Kontrasepsi Dalam Rahim (AKDR) Tahun 2018

\begin{tabular}{|c|c|c|c|c|c|c|c|c|}
\hline \multirow{3}{*}{ Paritas } & \multicolumn{4}{|c|}{ Ibu Yang Memilih Kontrasepsi AKDR } & \multirow{2}{*}{\multicolumn{2}{|c|}{ Total }} & \multirow{3}{*}{ P-value } & \multirow{3}{*}{ OR } \\
\hline & \multicolumn{2}{|c|}{$\mathrm{Ya}$} & \multicolumn{2}{|c|}{ Tidak } & & & & \\
\hline & $\mathrm{F}$ & $\%$ & $\mathrm{~F}$ & $\%$ & $\mathrm{~F}$ & $\%$ & & \\
\hline 1-3 anak & 27 & 32,9 & 17 & 20,7 & 44 & 100 & & \\
\hline$>3$ anak & 11 & 13,4 & 27 & 33 & 38 & 100 & 0,007 & 3,898 \\
\hline Total & 38 & 46,3 & 44 & 53,7 & 82 & 100 & & \\
\hline
\end{tabular}

\section{Kesimpulan}

$$
\text { Kesimpulan dalam penelitian }
$$
dengan judul Parameter reproduktif yang berhubungan dengan kejadian hipertensi pada perempuan adalah bahwa umur dan pekerjaan mempunyai hubungan dengan kejadian hipertensi pada wanita usia reproduktif sedangkan paritas, dan lama kontrasepsi kb hormonal justru tidak ada hubungannya dengan kejadian hipertensi pada wanita usia reproduktif.

\section{Daftar Pustaka}

Arda, Z. A., Ali, R. \& Mustapa, M. (2018) 'Hipertensi dan Faktor Risikonya di Puskesmas Motolohu Kabupaten Pohuwato', Gorontalo Journal of Public Health, 1(1), 32.

Ardiansyah, M. (2012) Medikal Bedah Untuk Mahasiswa. Yogyakarta: Diva Press.

Arif, D. \& Hartinah, D. (2013). Faktor-faktor yang berhubungan dengan kejadian hipertensi pada lansia di Pusling Desa Klumpit UPT Puskesmas Gribig Kabupaten Kudus, Jurnal Ilmu Keperawatan dan Kebidanan, 4(2), 18-34.

Dinkes Prov Jateng (2019) 'Profil Jateng 2018', pp. $2-6$.

Fauzi, I. (2014) Buku Pintar Deteksi Dini Gejala, \& Pengobatan Asam Urat, Diabetes \& Hipertensi. Yogyakarta: Araska. 
Giubertoni, E. et al. (2013) 'Parity as predictor of early hypertension during menopausal transition', Journal of Hypertension, 31(3), 501-507.

Kartikasari, A. N., Chasani, S., \& Ismail, A. (2012). Faktor Risiko Hipertensi pada Masyarakat di Desa Kabongan Kidul, Kabupaten Rembang (Doctoral dissertation, Fakultas Kedokteran).

Kementerian Kesehatan RI. (2013). Gambaran Kesehatan Lanjut Usia di Indonesia. Jakarta: Pusat Data dan Informasi Kementerian Kesehatan RI.

Kersten, F. A. M. (2015). Overtreatment in couples with unexplained infertility, Human Reproduction, 30(1), 71-80.

Pemkot Semarang. (2019). Profil Kabupaten/Kota, Pemkot Semarang.

Prayitno, A. (2013). Faktor-Faktor Yang Berhubungan Dengan Tekanan Darah Di Puskesmas Telaga Murni, Cikarang Barat Tahun 2012.

Riskesdas, K. (2018) 'Hasil Utama Riset Kesehata Dasar (RISKESDAS)', Journal of Physics A: Mathematical and Theoretical,
44(8), 1-200.

Suryandari, R. (2009). Hubungan antara kadar hemoglobin, trombosit, dan feritin dengan kejadian hipertensi pulmonal pada penderita talasemia anak di RSUD $d r$. Moewardi Surakarta Doctoral Dissertation Sebelas Maret University.

Seow, L. S. E., Subramaniam, M., Abdin, E., Vaingankar, J. A., \& Chong, S. A. (2015). Hypertension and its associated risks among Singapore elderly residential population. Journal of Clinical Gerontology and Geriatrics, 6(4), 125-132.

Sundari, A. (2018). Parameter Reproduktif (Umur, Paritas Dan Lama Penggunaan Kontrasepsi Hormonal) Yang Berhubungan Dengan Kejadian Hipertensi Pada Lansia Perempuan Di Puskesmas Tlogosari Kulon. Skripsi. 2018

Sugiharto, A. (2007). Faktor-Faktor Resiko Hipertensi Grade II Pada Masyarakat (Studi Kasus di Kabupaten Karang Anyar). Tesis. Program Pasca Sarjana Universitas Diponegoro. Semarang.

WHO. (2015). Cardiovascular diseases (CVDs) World Health Organization. 


\section{1}

This page itentionally left blank. 